\title{
Environmental Value of Housing Gardens in Urban Landscape: A Case Study of Tusba/Van Detached Home Gardens
}

\author{
Betul Yilmaz \\ Van Metropolitan Municipality, Directorate of Parks and Gardens, Van/Turkey \\ E-mail: betulyilmaz629@gmail.com \\ Feran Asur \\ Department of Landscape Architecture, Faculty of Architecture-Design \\ Van Yuzuncu Yil University, 65080 \\ Van/Turkey \\ E-mail: feranekasur@gmail.com
}

\begin{abstract}
Residential gardens; increasing the quality of urban landscape by increasing the agricultural skills of the people of the city, providing economic gain, being one of the most effective methods of combating food, improving air quality, contributing to the reduction of $\mathrm{CO} 2$ emissions and temperature, enabling social activities, recreation and leisure time opportunities has positive effects. The detached house gardens in the city of Van are characterized by multifunctionality, which gives people different advantages as in other cities. The aim of this study is to determine the place, properties and importance of residential gardens in urban life in urban area. In the study, detached house gardens, which are important traditions, were found in the neighborhoods of Tusba in Van. The literature on the subject has been searched, geographic information system software has been used to determine the available area uses and on-site observation and analysis methods have been used. As a result, the neighborhood with the highest number of residences with gardens was identified as Altıntepe Quarter with 893 residences. At the end of the study, the aim of this study is to develop the suggestions for the sustainability of the garden culture by revealing the role of detached house gardens in the city which existed throughout history and whose examples are decreasing today.
\end{abstract}

Keywords: Urban landscape, cultural heritage, detached house gardens, Tusba county.

DOI: $10.7176 /$ JSTR/6-01-07

\section{Kentsel Peyzajda Konut Bahçelerinin Çevresel Değeri: Tuşba/Van Örneğinde Müstakil EV Bahçeleri}

\begin{abstract}
Özet
Konut bahçeleri; kentsel peyzaj kalitesini arttırarak kent halkının tarımsal becerilerinin artması, ekonomik kazanç sağlaması, hazır gıdaya karşı verilebilecek en etkili mücadele yöntemlerinden biri olması, hava kalitesinin iyileştirilmesi, CO2 emisyonlarının ve sıcaklığın azaltılmasına katkıda bulunması, sosyal etkinliklere olanak sağlama, dinlenme ve boş zaman değerlendirme olanakları gibi birçok olumlu etkilerine sahiptir. Van kentindeki müstakil ev bahçeleri de diğer kentlerde olduğu gibi insanlara farklı avantajlar sağlayan çok işlevlilik ile karakterizedir. Çalışmanın amacı; Van Kentsel alanında konut bahçelerinin şehir ortamında insan hayatındaki yeri, özellikleri ve önemi belirlemektir. Çalışmada önemli gelenek olan müstakil ev bahçeleri Van kenti Tuşba İlçesinde en çok bulunan mahalleler tespit edilmiştir. Konuyla ilgili literatür taranmış, mevcut alan kullanımlarının belirlemesinde coğrafi bilgi sistemi yazılımından yararlanmış, yerinde gözlem ve analiz yöntemleri kullanılmıştır. Sonuçta en çok bahçeli konutların bulunduğu mahalle 893 konut ile Altıntepe Mahallesi olarak tespit edilmiştir. Çalışma sonunda kentsel tasarımda tarih boyunca var olan ve günümüzde örnekleri azalan kentteki müstakil ev bahçelerini yaşanabilir ve sürdürülebilir kentteki rolü ortaya koyarak bahçe kültürünün sürdürülebilirliğini sağlamak için öneriler geliştirmektir.
\end{abstract}

Anahtar Kelime: Kentsel peyzaj, kültürel miras, müstakil ev bahçeleri, Tuşba İlçesi

65 | P a g e

www.iiste.org 


\section{Giriş}

Kentlerdeki hızlı nüfus artışı ve yeni yerleşim alanları sonucu oluşan yoğun yapılaşma geleneksel doku üzerine baskı oluşturarak, kentler için önemli bir faaliyet alanı olan müstakil ev bahçeleri kültürünün kaybetmesine de neden olmaktadır. Somut ve soyut miraslarımızı korumak, geçmişin izlerini bugüne ve geleceğe taşımak kapsamında bu bahçe kültürünün sürdürülebilirliğini sağlamak kolektif belleğin geleceği biçimlendirmesini de etkin kılacaktır. Kentler, sürekli toplumsal gelişme içinde bulunan ve toplumun, yerleşme, barınma, gidiş geliş, çalışma, dinlenme, eğlenme gibi ihtiyaçlarının karşılandığg, pek az kimsenin tarımsal uğraşlarda bulunduğu, köylere nazaran nüfus açısından daha yoğun olan ve küçük komşuluk birimlerinden oluşan yerleşme birimi olarak tanımlanmaktadır (Keleş, 1998). Doğadan uzak yerleşmeler olan bir çok kent özellik Sanayi Devriminden sonra günümüze kadar daha belirgin bir durumda beton binalarla olan görüntülere bürünmüşler. Bir kentteki bitki türü, sayısı ve kullanımı; yerleşimin coğrafik durumuna, sosyo-ekonomik yapıya, kent tarihine, alan kullanımlarına, yerel yönetimlerin tutumuna ve kişisel tercihlere bağlı olarak değişebilir (Jim, 1987; Talarchek, 1990; Welch, 1994). Kentsel alanda konut bahçeleri kentte yaşayan kişilerin boş zamanlarında süs bitkileri, meyve ve sebze üretiminde kullandıkları ve peyzaj değeri olan küçük tarım parselleridir. Türkiye'de bu bahçeler; küçük bahçeler, halk (topluluk) bahçeleri, kent bahçeleri, hobi bahçeleri ve kişiye özel kent bahçeleri olarak bilinmektedir (Hassan, 1995; Kılıç, 1995). Bu bahçeler insanların doğa ile olan ilişkilerini yeniden düzenleme, ekonomik fayda sağlama, kentlere yeşil alan kazandırma açısından önemlidir. Yeşil alanların insan sağlığında, insan psikolojisi üzerine olumlu etkileri vardır bir yeri vardır. İnsanlar huzurlu ve sakin zamanlar geçirebilmek için yeşil alanları tercih ederler (Atanur, 2000; İçmeli, 2003; Yazıcı vd., 2016; Yazıcı ve Akça, 2019). Konut bahçeleri; kentsel peyzaj kalitesini arttırarak dekoratif bir kaynak sağlamasının yanı sıra kent halkının tarımsal becerilerinin artması, ekonomik kazanç sağlaması, hazır gıdaya karşı verilebilecek en etkili mücadele yöntemlerinden biri olması, hava kalitesinin iyileştirilmesi, CO2 emisyonlarının ve sıcaklığın azaltılmasına, biyoçeşitliliğin korumasına katkıda bulunması, sosyal etkinliklere olanak sağlama, dinlenme ve boş zaman değerlendirme olanakları gibi birçok olumlu etkilere sahiptir (Hodgkin, 2001; Van Veenhuizen, 2006; Viljoen ve ark., 2009). Son yıllarda nüfusa bağlı kent merkezinin hızlı gelişimi, merkeze yakın çevrede bulunan yeşil alanların azalmasına ve bazen de bir bölümünün tamamen yok olmasına neden olmuştur. Bu süreçte kentin eski yerleşim alanlarında bulunan yeşil alanlar ve büyük bahçeli eski evler korunamamış ve var olan alanlar da küçültülmekte veya tamamen yok olması görünmektedir. Van ve yakın çevresi son yüz yıla kadar Kuzey Mezopotamya ile ticari ve kültürel ilişkileri olmuştur. Mezopotamya'dan kültürel açıdan etkilendiği birçok alanlardan biri de Mezopotamya'da gelişip dünyaya yayılan bahçe kurma ve düzenlemeleridir (Alp, 2007).

Bu çalışmada Van Kentsel alanında hala mevcut olan konut bahçelerinin şehir ortamında insan hayatındaki yeri, özellikleri ve önemi belirlenmeyi amaçlanmıştır. Bu doğrultuda Van ili Tuşba ilçesinde bahçeli evlerin daha çok yer aldığı mahalleler araştırılmıştır. Bahçeli konutların yoğun olarak bulunduğu 5 mahalle tespit edilerek incelenmiştir. Bu bağlamda belleklerde önemli yeri olan bahçe kültürünün sürdürülebilirliğini sağlamak için öneriler geliştirilmiştir.

\section{Materyal Ve Yöntem}

Araştırmanın ana materyalini Van Tuşba ilçe sınırlarında (Şekil 1.) yoğun bulunan ve alternatif yeşil alan kaynakları olarak değerlendirilebilen konut bahçeleri oluşturmaktadır. Van ili merkez ilçesi olan Tuşba, 67 mahalle sınırlarını kapsamaktadır. Van kentinin merkezi alanında en çok bahçeli evleri olan mahalleler araştırılmıştır ve en çok Tuşba ilçesinde bahçeli konutların yer aldığı tespit edilmiştir. Yine Tuşba ilçesinde en çok bahçeli evlerin bulunduğu mahalleler incelenerek 5 mahalle ele alınmıştır. Yardımcı materyal olarak da belediyeden alınan sözlü ve yazılı bilgiler, 1/25.000 ölçekli Van Tuşba ilçesi ve yakın çevresi Devlet İstatistik Enstitüsü'nden alınan nüfus verileri, belediyeden alınan bilgiler, Nazım İmar Planı ve konu ile ilgili çalışma ve araştırmalar kullanılmıştır. Çalışmada yerinde inceleme ve gözlem yapılarak veri toplama, etüt ve analize dayalı peyzaj araştırma yöntemleri kullanılmıştır. Mevcut alan kullanımlarının belirlemesi ve alan hesaplamalarında coğrafi bilgi sistemi (GIS) yazılımından yararlanmış, ilçenin fiziksel durumu, nazım ve uygulama imar planları ve çekilen fotoğraflar ile belirlenmiştir. 


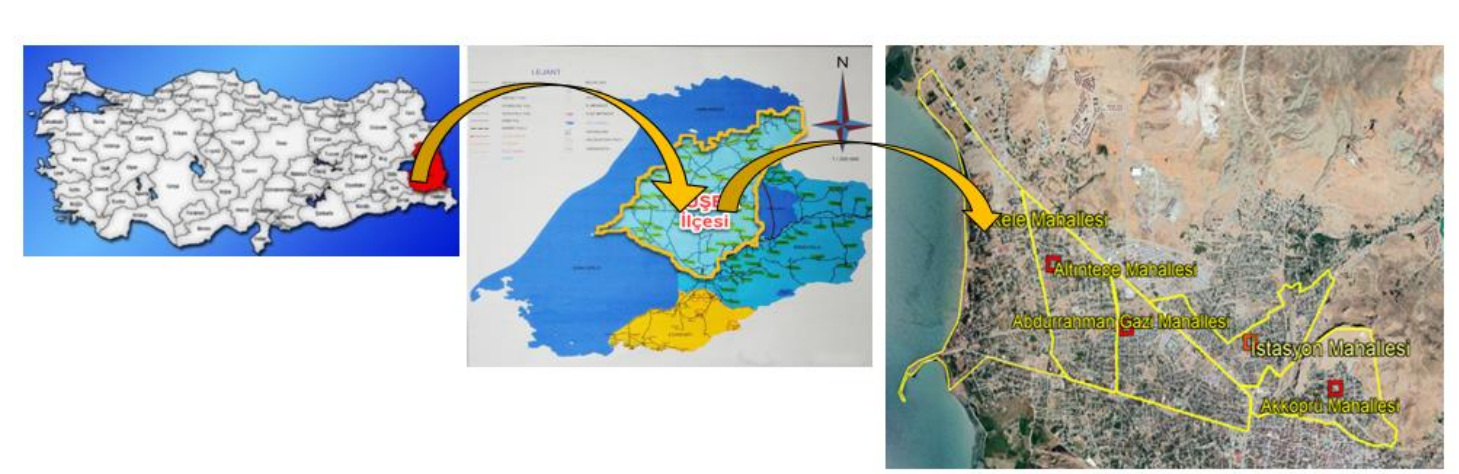

\section{Bulgular}

Şekil 1. Çalışma alanı (Google Earth Pro, 2019)

Van kentsel alanda en eski örnekler son kalan kent içi tarım alanlarını barındıran eski müstakil konut bahçelerini genelde kentin merkezi kısmında olmayan fakat merkezden daha mesafeli bölgelerde bazen yüksek katlı apartman ve sitelerin arasında sıkışmış vaziyette görmek mümkündür. Yapılan incelemeye göre Tuşba İlçesinde bahçeli müstakil evler en çok 5 mahallede yer almıştır. Mahallelerdeki bahçeli ev sakinleri, peyzaj değeri olan bahçeyi amaç ve iklim koşullarına uygun olarak süs bitkileri (Tablo 1), sebze, meyve vb. tarımsal faaliyetlerde kullanmaktadırlar. Bahçe sahipleri genelde hem üretken hem de sosyal bir mekan olarak bu bahçeleri korumaya çalışılıyorlar. Bu bahçeler, mahallelinin mevsiminde taze sebze ve meyveleri yemelerinin yanında yerli flora ve faunanın korunmasına da katkı sağlamaktadır. Bu bahçeler insanların birbirlerinden öğrendiği ve öğrenme kültürünü geliştirdiği katılımcı süreçleri destekleyen alanlardır. Üretilen yeşillikler içinde daha çok yerel halk tarafından kullanılan bazı yeşillikler olan: kişniş, merze ve reyhanın yanı sıra herkes tarafından bilinen nane, maydanoz, semizotu, dereotu, roka, pazı, kıvırcık, kuzukulağı ve vahşi ısırgan yer almaktadır. Yine bahçelerde yer alan meyve türleri genelde vişne, elem, kayısı, kiraz ve armuttan oluşmaktadır. Bahçe sahipleri genelde yerli meyve türlerinin bahçelerinde yetiştirilmesine önem vermektedir.

Alp (2007)'a göre mevcut olan süs bitkilerini sınıflandırdığında dört adet çok yıllık mevsimlik çiçek, dokuz adet geofit, 13 adet çalı, 10 adet ağaç ve üç adet sarılıcı-tırmanıcı bitki türü bulunmaktadır. Bu türlerin çoğunluğu nisan, mayıs ve haziran aylarında çiçek açmaktadır. Bunların içinde güllerin kullanımı daha çok görülmektedir. Genelde Van bahçelerinde Narcissus poeticus ve Hemerocallis fulva gibi geofitler ve Aster ssp. gibi mevsimlik çiçeklerin büyük kısmı egzotik bitkileridir. Bölgenin yabani geofit ve tek yıllık bitkiler açısından zengin olmasına rağmen (Davis, 1965-1988; Koyuncu ve ark., 1998) bunların çok az bir bölümünün bahçelerde süs bitkisi olarak kullanılması dikkat çekicidir.

$\mathrm{Bu}$ bahçelerde bahçe ürünlerinden bitki yetiştiriciliğinin dışında zaman zaman küçükbaş ve az da olsa büyük baş hayvan yetiştiriciliğinin yapıldığı da görünmektedir. Bu durumda onların etleri, süt ve süt ürünlerinden de faydalanma olanağı sağlanmaktadır.

Tablo 1. Çalışma alanlarında yaygın kullanım gösteren süs bitkileri

\begin{tabular}{|c|c|c|c|}
\hline \multirow{17}{*}{$\begin{array}{l}\text { Bitki } \\
\text { Türleri }\end{array}$} & Bilimsel Adı & Türkce Adı & Kullanım sıklığı \\
\hline & Salix babylonica & Salkım Söğüt & Sik \\
\hline & Tamarix ssp. & Beyaz ve Pembe Çiçekli Ilgın & $\mathrm{Az}$ \\
\hline & Elaeagnus ssp. & İğde & S1k \\
\hline & Fraxsinus Excelsior & Adi Dişbudak & Orta \\
\hline & Viburnum Tinus & Kartopu & $\mathrm{Az}$ \\
\hline & Alcea rosea & Hatmi çiçeği & Sik \\
\hline & Syringa vulgaris & Leylak & Çok sık \\
\hline & Coreopsis grandiflora & Koyungözü & Sik \\
\hline & Tagetes petula & Kadife & Çok s1k \\
\hline & Petunia hybrida & Petunya & $\mathrm{Az}$ \\
\hline & Narcissus poeticus & Zerrin kadeh & Orta \\
\hline & Aster spp. Eylül Çiçeğ $i$ & Eylül Çiçeği & Orta \\
\hline & Dahlia ssp. & Y1ldız çiçeği & Orta \\
\hline & Iris germanica & Mezar irisi Zambak & $A z$ \\
\hline & Rosa canina & Kuşburnu & Çok s1k \\
\hline & Solanum crispum & Sonbahar leylağı & Orta \\
\hline
\end{tabular}


Yapılan bu çalışmada peyzaj ve çevresel değerleri açısından incelenen konut bahçeleri; Altıntepe, Akköprü, İstasyon, İskele, Abdurrahman Gazi mahallelerinde yer alamaktadır.

3.1.Abdurrahman Gazi Mahallesi; Toplam nüfusu 18.032 kişi olan bu mahalle yaklaşık $2.89 \mathrm{~km}^{2} \mathrm{kadar}$ bir alanı kaplamaktadır. Müstakil evler çoğunlukla eski yapılardan kalma iken son yıllarda inşa edilen konutların çok katlı olduğu görünmektedir. Mahalle içerisinde yer alan bahçeli konutlar, kentin yeşil alan düzeyine katkı sağlayacak düzeyde değil ve peyzaj açısından çok etkin role sahip değildir. İncelemelerde bahçeli konut sahiplerinin özellikle sebze-meyve faaliyetlerini yürüten seralarının olduğu Belediyelerden tohum ve fide konusunda destek alarak geçimlerine katkı sağladıkları ayrıca kentin yeşil dokusunu korudukları gözlemlenmiştir (Şekil 2, 3,4.).

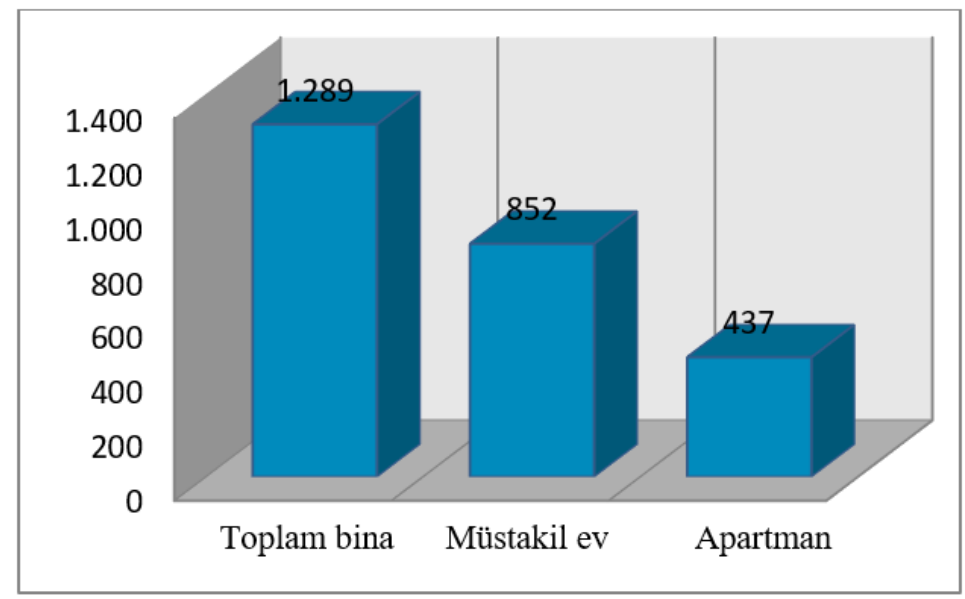

Şekil 2. Abdurrahman Gazi mahallesindeki toplam bina, müstakil ev ve apartman durum
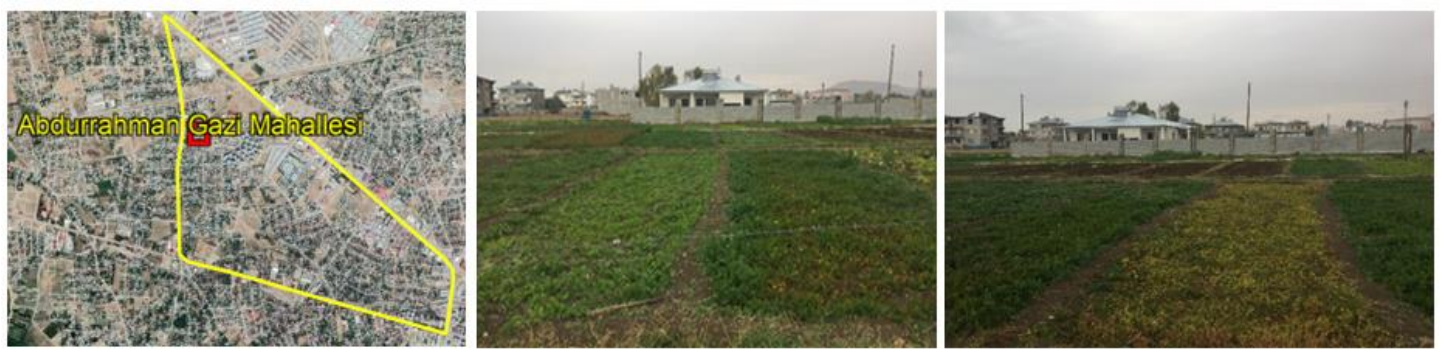

\section{Şekil 3.A.Gazi Mah. Konumu}

Şekil 4 A.Gazi Mahal. konut bahçesi görüntüleri

3.2. Altıntepe Mahallesi; Toplam nüfusu 13.907 kişi olan mahallenin kapladığ dir. Müstakil evleri tek, iki ve çok katlı olarak inşa edilmiştir. Genelde konut sakinleri kendilerine ait olan bahçe alanını değişik kuşatma elemanlarıyla sınırlandırarak diğer konut alanlarından bağımsız olarak düzenlemiştir (Şekil 5, 6, 7.). İncelemelerde müstakil ev bahçelerinde konut sahibinin istekleri ön planda görülmüştür ve görsel peyzaj açısından etkin değere sahiptirler. Kişilerin ekonomik durumu ile orantılı bahçe mahsullerine yer verilmiştir, konut sahiplerine ekonomik katkı sağlamaktadır. 


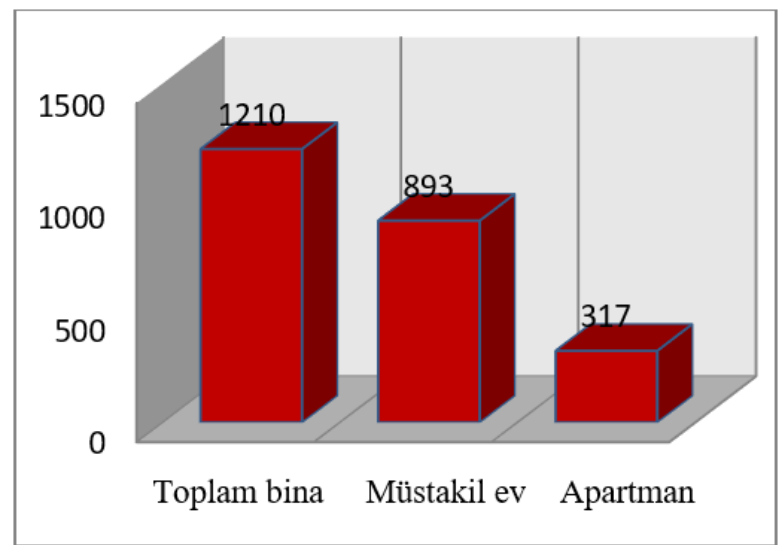

Şekil 5. Altıntepe Mahallesindeki toplam bina, müstakil ev ve apartman durumu
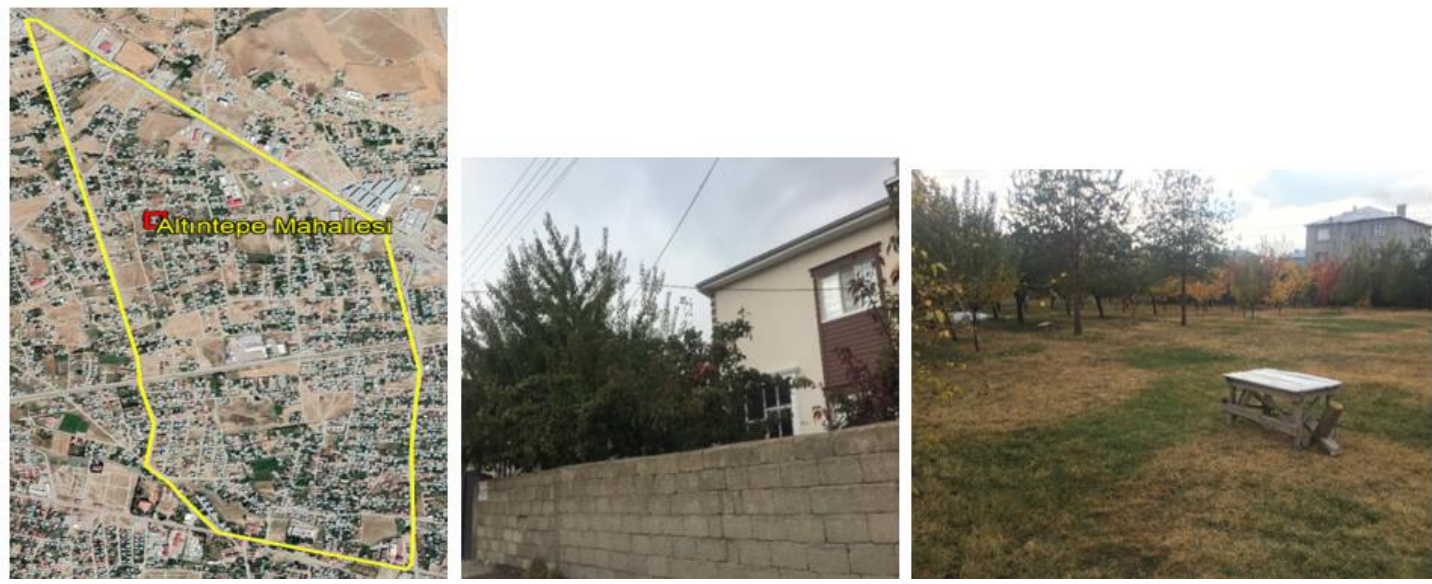

Şekil 6. Altıntepe Mah. Konumu Şekil 7. Altıntepe Mahallesinden konut bahçesi görüntüleri

3.3.İskele Mahallesi; Toplam nüfusu 11.819 kişi ve kapladığı alan yaklaşık $4.98 \mathrm{~km}^{2}$ olan bu mahallede yer alan ev bahçeleri Altıntepe mahallesine benzer özellik taşımaktadır. Özellikle her konutta meyve bahçeleri, seralarda ve tarlalarda sebze türlerinin yoğun olarak kullanıldığ 1 tespit edilmiştir. Bunu yanı sıra yöreye özgü olan ve estetik ve görsel peyzaj kalitesi ile ön plana çıkan süs bitkileri de incelenen birçok konut bahçesinde tespit edilmiştir (Şekil 8, 9, 10).

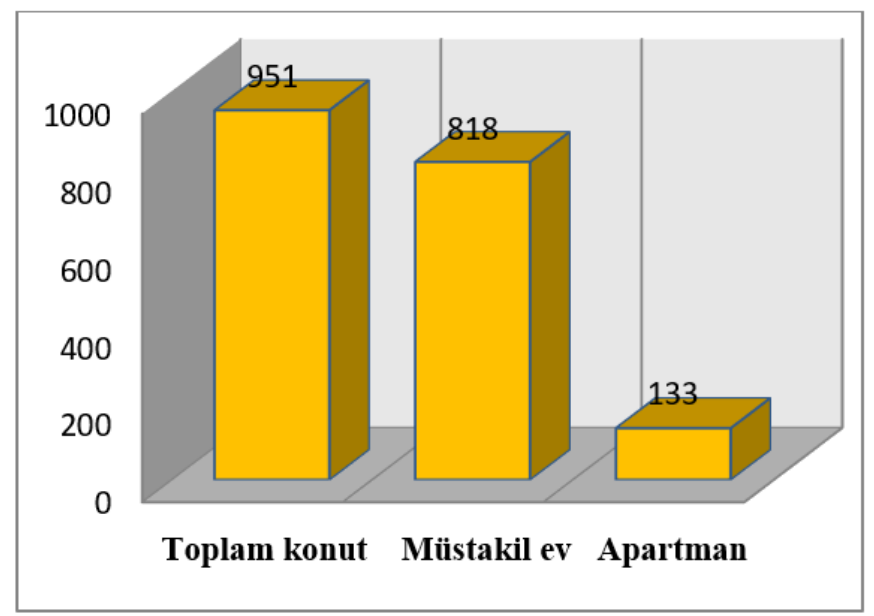

Şekil 8. İskele Mahallesindeki toplam bina, müstakil ev ve apartman durumu 


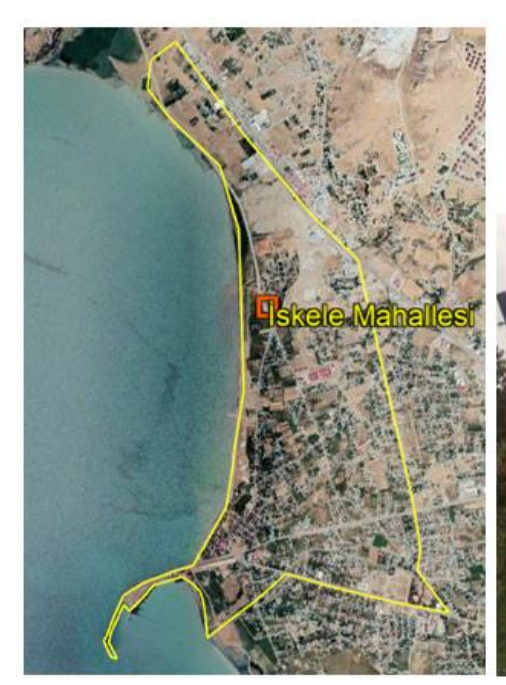

Şekil 9. İskele mahallesi konumu
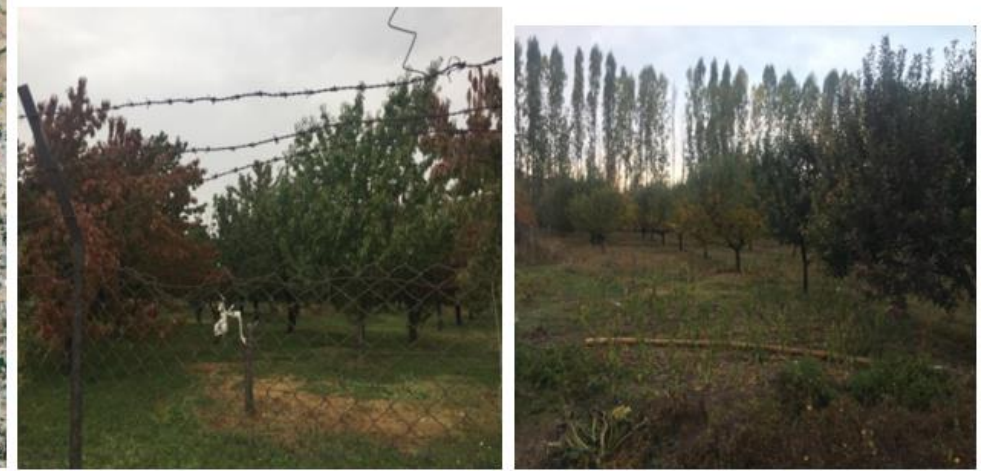

Şekil 10. İskele Mahallesindeki konut bahçelerinden görüntü

3.4.Akköprü Mahallesi; Toplam nüfusu 13.314 kişi ve kapladığı alna yaklaşık $2.68 \mathrm{~km}^{2} \mathrm{olan}$ bu mahallede müstakil ev sayısı diğer mahallere oranla daha az olduğu gözlemlenmiştir. Özellikle yüksek katlı binalar mahalle içerisinde yoğun bir dağılış gösterdiği için bahçelerin peyzaj değeri çok belirgin olmamaktadır. Meyve bahçelerinin fazla olduğu ve kümes hayvancılığına da yer verildiği görülmüştür. Bazı bahçeler sadece sebze yetiştirmek amacıyla oluşturulmuştur (Şekil 11, 12, 13.).

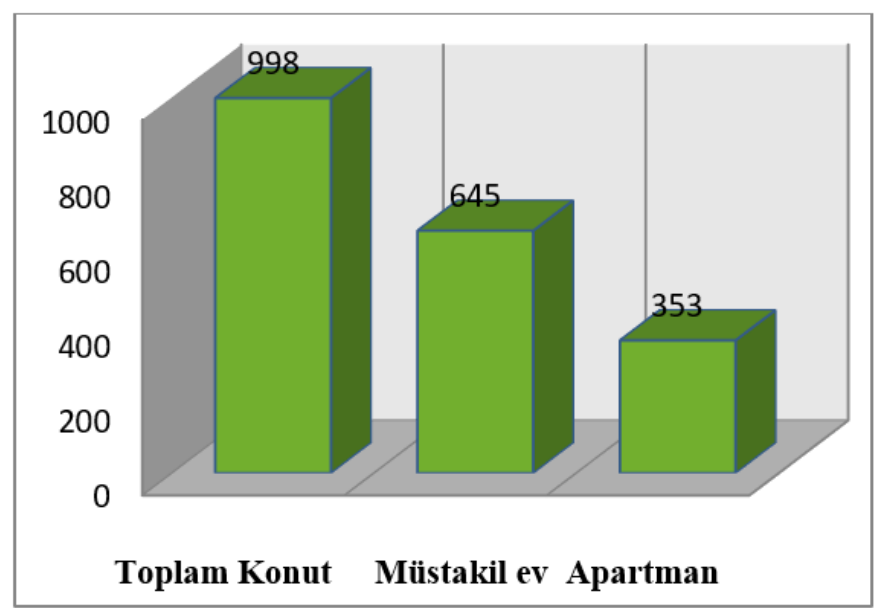

Şekil 11. Akköprü Mahallesinde toplam bina, müstakil ev ve apartman durum

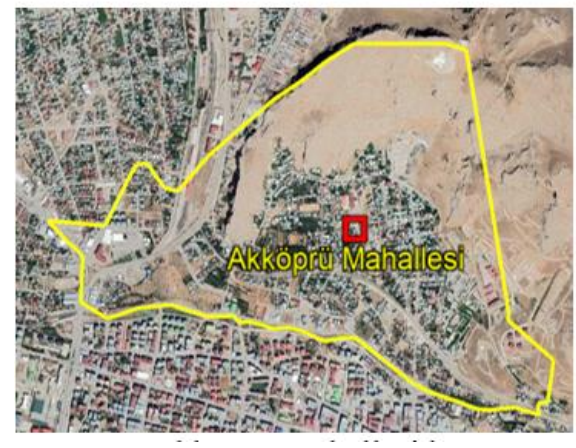

Şekil 12. Akköprü Mahallesi konumu
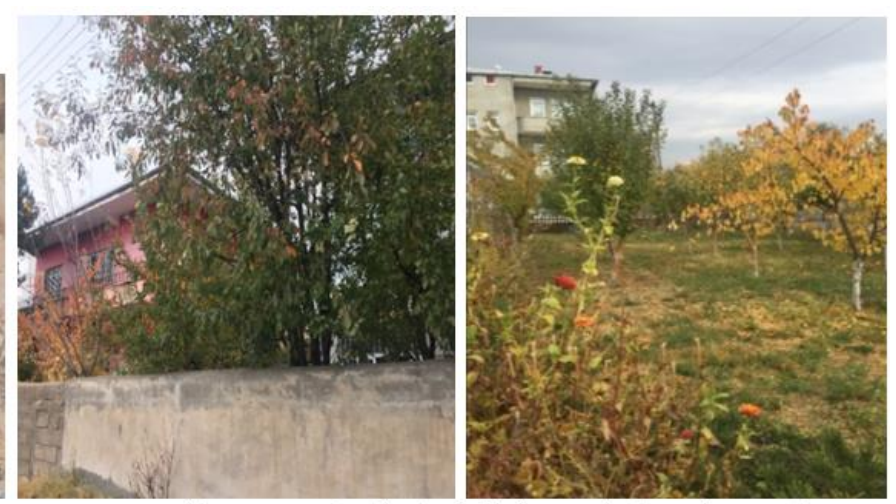

Şekil 13. Akköprü Mahallesindeki konut bahçesi örneği

70 | P a g e 
3.5.İstasyon Mahallesi; Toplam nüfusu 11.882 kişi ve kapladığı alan yaklaşı $2.14 \mathrm{~km}^{2}$ dir. Bu mahallede yüksek oranda çok katlı binaların olduğu müstakil ev sayısının fazla olmadığı görülmüşsür. İnceleme yapılan müstakil ev sahipleri bahçelerinin çoğunlukla sebze-meyve yetiştirmek amacıyla kullanmaktadır (Şekil 14,15, 16.).

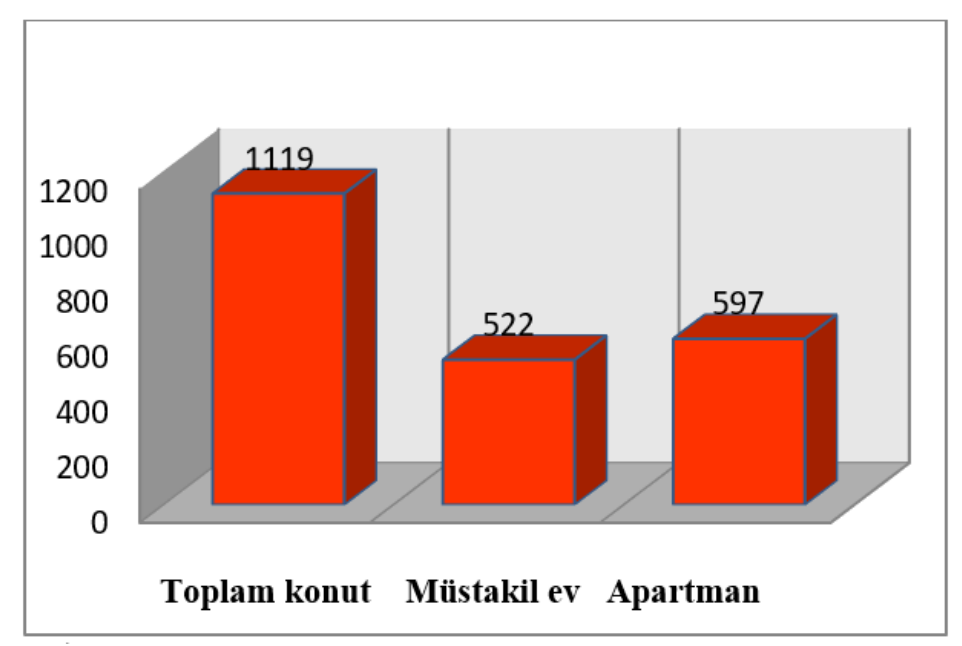

Şekil 14. İstasyon Mahallesindeki toplam bina, müstakil ev ve apartman durumu
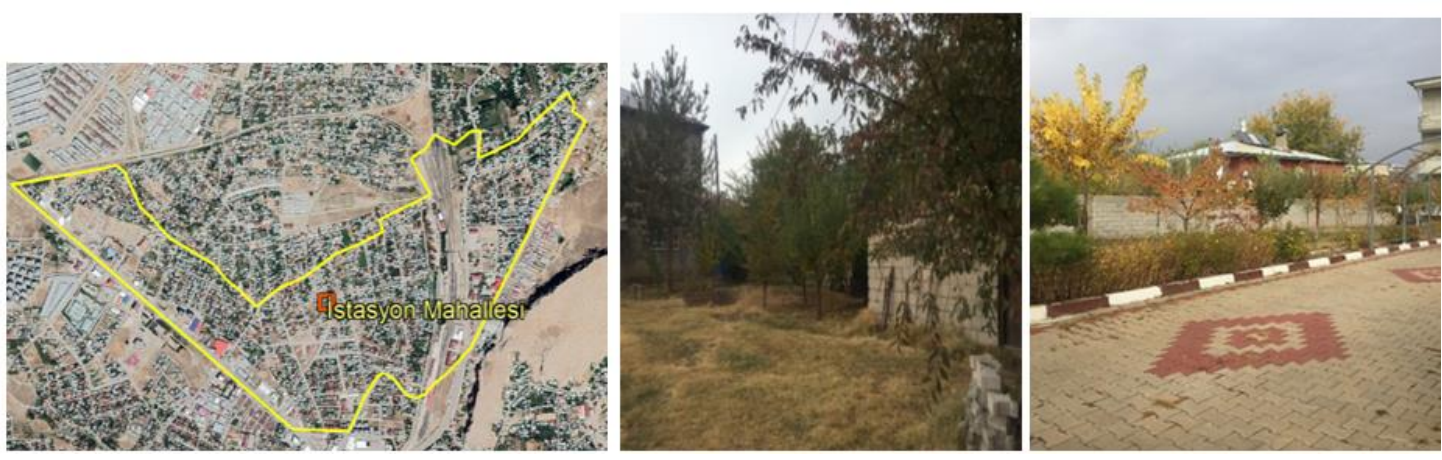

Şekil 15. İstasyon Mahallesi konumu

Şekil 16. İstasyon Mahallesinden konut bahçesi görüntüsü

Genel olarak seçilen mahallelerde yer alan konutlar, halkın sosyo-kültürel yapılarına dayanarak bahçe kullanımı bakımından benzerlikler göstermektedir. Kentin tam merkezi kısımlarında çok katlı binalar inşa edilmiş ve alt katları ticari amaçla kullanıma açılmıştır. Son yıllarda görülen yoğun yapılaşma ile tüm boşluklar binalarla doldurulduğundan kent merkezindeki konutlarda kentsel peyzaja katkı sağlayabilen bahçe oluşturmak için yer sıkıntısı yaşanmaktadır. Bu açıdan bu alanlardaki konutlar ya bahçeye sahip değiller ya da bahçeleri çok küçük kalmıştır.

\section{Sonuç Ve Öneriler}

İnsanların fiziksel ve ruhsal sağlı̆ı yönünden oldukça önemli rol oynayan bahçeye, tarihsel süreçte önemli ölçüde değer görmüştür. Önceleri tarımsal amaçla kullanılan bahçeler, zamanla kişilerin ekonomik, zevk ve kültür yapılarına göre biçimlenmiştir. Günümüzde kentler çeşitli nedenlerle aşırı yoğunlaşması, arsa rantlarını artırarak, kentsel peyzaj imajını değiştiren yeşil alan gibi kamusal alanlara ayrılması gereken bölgeleri sınırlamaktadır (Atmış vd., 2007; Önder ve Polat, 2012). Nüfus artışı ve göçler sonucunda meydana gelen konut sorunu, bahçeli konumdaki yaşam alanları, ortak yaşam alanları bulunan, yüksek katlı yapılardan oluşan, toplu konut alanlarına yöneltmiştir. Dikey yapıların yanında, ev bahçeleri yapılarındaki doğal yeşil alanların en yakın taklitleri olarak yatay yapıya sahipler. $\mathrm{Bu}$ çalışmada; kentsel peyzaj bağlamında Tuşba ilçe sınırları içerisinde bahçe kültürünün yoğun olarak sürdürüldüğün mahallelerin konut bahçeleri incelenmiştir. Bu incelemeler sonucunda, seçilen 5 mahalle

71 I P a g e 
için konut bahçeleri oldukça büyük alana sahip oldukları, ancak yeterli fonksiyonel bulunmadığ 1 tespit edilmiştir. TUİK verilerine göre çalışma alanı olarak seçilen 5 mahallenin 2018 yılı nüfus oranları belirtilmiştir. Bu şekilde kişi başına düşen pasif yeşil alan miktarı standartlar üzerinde olmasına karşın, aktif yeşil alanların standartlara (kişi başına $7 \mathrm{~m}^{2} /$ kişi) ulaşamadığ 1 hesaplanmaktadır. Yapılan çalışmada 5 mahalleden en çok Altın Tepe mahallesinde bahçeli konut mevcut olup en az da İstasyon mahallesinde bahçeli konut bulunmaktadır (Şekil 17). Konut sakinlerinin geleneksel yaşamlarına bağlılığ kültürel yönden devam ederken; fiziksel yönden de bu sürekliliği sağlanamadığı saptanmıştır. Özellikle son birkaç yıl içerisinde Van Büyükşehir Belediyesi ve İpekyolu Belediyesi merkez ve köyler için bahçeli konut sahiplerine tohum ve fide desteği sağlayarak yeni projeler üreterek bu geleneği sürdürülebilir hale getirmeyi hedeflemişlerdir. Seçilen mahallelerde konut sahipleri bahçe sınırları içerisinde üretim yaparak güvenilir gıda tüketimine başlamış aynı zamanda ürettikleri gıdaların satışını yaprak ev ekonomilerine katkı sağlamaya başlamışlardır.

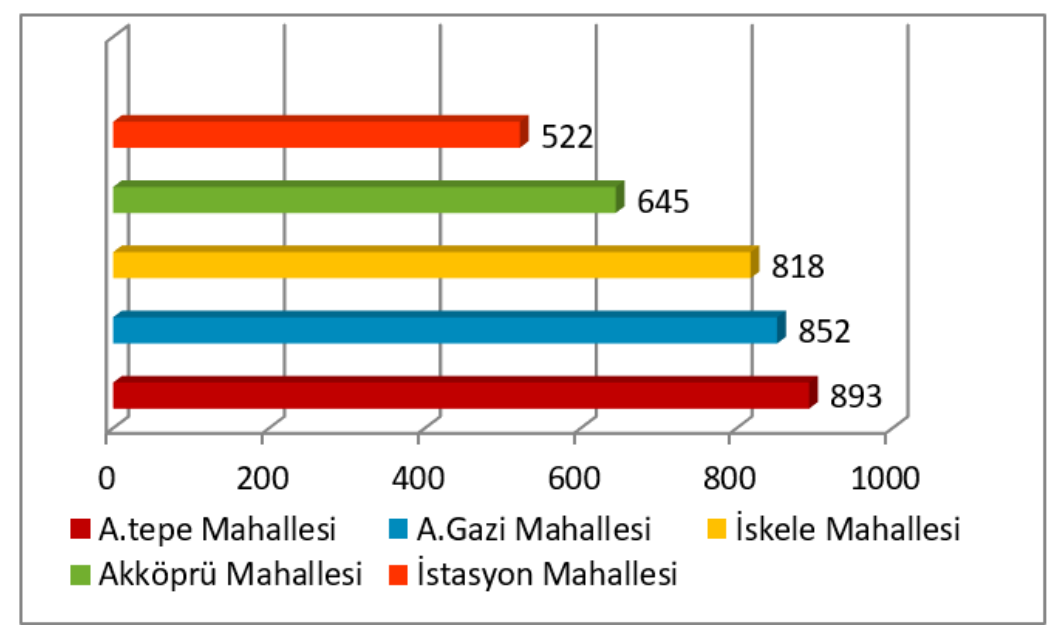

Şekil 17. Seçilen mahallelerde bahçeli konutların mevcut durumu

Konut sahipleri ile yapılan görüşmeler sırasında bahçe kültürünün devamlılığı konusunda verilen eğitim ve desteklerin büyük fayda sağladığı, mahalle sakinleri ve kent kullanıcıları için yüksek oranda tercih edilen özellikle ilkbahar ve yaz aylarında rekreatif amaçlı ziyaret edilen bahçeler önemli bir hal almıştır. Çalışmada sonucunda Abdurrahman Gazi mahallesinde bahçeli konut sayısı çok olduğu ortaya çıkmıştır. Bahçelerin işlevsel etkileri ile birlikte kent peyzajındaki görsel etkilerinin de büyük oranda önem taşıdığı için Abdurrahman Gazi mahallesinde bahçeli konutları korumak ve yaymak amacıyla yerel yöneticilerin ciddi girişimleri ve desteklerinin yer alması gerekmektedir. Ekolojik koşullara uygun ve biyoçeşitliliğ $i$ desteklemek amaciyla bahçelerde doğru bitki seçimleri amacıyla üniversitedeki ilgili birimlerden bilimsel anlamda destek almaları sağlanmalıdır. Bunların sonucunda geleneksel dokunun sürdürülmesi sağlanarak kent kapsamında bu mahalle örnek teşkil edebilecek duruma gelebilir. Tarım destekli bu tür projelerin arttırılması, eğitimler verilmesi, kullanıcıların bilinçlendirilmesi bu tür çalışmaların kent genelinde sürdürülebilmesi gelecek için de yeşil alan miktarını ve konut bahçelerinin peyzaj değerini büyük oranda arttıracaktır. Bu durumda bahçe kültürünün sürdürülebilirliğini sağlayarak kolektif belleğin geleceği biçimlendirmesini de etkin kılacaktır.

\section{Kaynakça}

Alp, Ş. (2007), Van Kenti ve Çevresindeki Geneleksel Konut Bahçelerinde Kullanılan Bitki Materyalinin Belirlenmesi. Yüzüncü Yıl Üniversitesi Tarım Bilimleri Dergisi, 17(1), 1-6.

Atanur, G.S. (2000), Planlı Konut Alanlarında Çevre Kalitesi Sorunu Ve Peyzaj Mimarının Sorumluluğu. TMMOB Peyzaj Mimarları Odası Peyzaj Mimarlığı Kongresi, 91-96, Ankara. 
Atmış, E., Özden, S., Lise, W. (2007), Urbanization pressures on the natural forests in Turkey: an overview. Urban for Urban Green.

Davis, P.H., (1965-1988), Flora of Turkey and East Aegean Islands, I-XI volumes, Edinburgh Un. Press, Edinburgh.

Hassan, B. (1995), Educational Modelsfor Community Garden Programs in the United Statesand Their Potential Application for Sub-Saharan Africa. PhD Thesis, Kansas StateUniversity, Department of Horticulture, ForestryandRecreationResources, Manhattan-Kansas.

Hodgkin, T. (2001), Home gardens and the maintenance of genetic diversity. In: Watson, J.W. and Eyzaguirre, P.B. (Eds.), Proceeding of the second International Home Garden Workshop, Biodiversity International, Rome, Italy, 14-18.

İçmeli, C. (2003), Kent Planlaması Davranış Psikolojisi, Basılmamış Ders Notları, Düzce.

Jim, C.Y. (1987), The status and prospects of urban trees in Hong Kong. Landscape Urban Planning $14,1-20$.

Keleş, R. (1993), Kentleşme Politikası, 504, İmge Kitabevi.

Kılıç, H. (1995), İzmir kent örneğinde küçük bahçeleri planlama olanakları üzerine araştırmalar. Yüksek Lisans Tezi, Ege Üniversitesi, İzmir.

Koyuncu, M., Demirkuş, N., Kaya, A., Aziret, A. (1998), Van Çevresi Geofitleri Üzerine Floristik Bir Araştırma. Yüzüncü Yı1 Üniversitesi, Araştırma Fonu (EF 97030 Nolu Proje), Van. 173 s.

Önder, S., Polat, A.T. (2012), Kentsel Açı-Yeşil Alanların Kent Yaşamındaki Yeri ve Önemi, Kentsel Peyzaj Alanlarının Oluşumu ve Bakım Esasları Semineri, Konya.

Talarchek, G.M. (1990), Urban forest of New Orleans: an explanatory analysis of relationships. Urban Goegr. 11, 1, 65-86.

TÜIK. (2015), Adrese Dayalı Nüfus Kayıt Sistemi. Türkiye İstatistik Kurumu. www.tuik.gov.tr

Van Büyük Şehir Belediyesi. 2019. https://van.bel.tr.

Van Veenhuizen, R. (2006), Cities Farming for the Future: Urban Agriculture for Green and Productive Cities. Ottawa.

Viljoen, A., Bohn, K., Tomkins, M. (2009), Places for People, Places for Plants: Evolving Thoughts on Continuous Productive Urban Landscapes. Proceedings of the Second International Conference on Landscape and Urban Horticulture. Department of Agroenvironmental Science and Technology (Dista), Faculty of Agriculture, University of Bologna, Italy: 38.

Welch, J.M. (1994), Street and trees of Boston: a comparison of urban forest structure. Landscape and Urban Planning 29, 131-143.

Yazici, K., Gulgun, B., \& Dursun, S. (2016). The Importance Of Appropriate Area Planning and Geographical Information Systems In Growing Ornamental Plants In Turkey. International Journal of Ecosystems And Ecology Science-IJEES, 6(2), 225-232.

Yazici, K., \& Akca, S. B. (2019). Determınation of Suttable Recreatıonal Areas Based On Expert Opınıon With Q-Sort Analysis; Boraboy Lake Natural Park (Amasya, Turkey). Fresenius Environmental Bulletin, 5(2), 3778-3786. 